\title{
Comprehensive Analysis of Laboratory Results of a Sjögren's Syndrome Patient Combining Autoimmune Hepatitis with Double Negatives of the Sjögren's Ayndrome Antigen A and B
}

\author{
Jianwei Zhou ${ }^{1, *}$, Cui Kong ${ }^{2}$, Zhaocai Zhang ${ }^{1}$, Xinke Chen $^{1}$, Shuo Shi ${ }^{1}$, Liang Han ${ }^{1}$ \\ ${ }^{1}$ Medical Laboratory, Affiliated Hospital of Jining Medical College, Shandong Province, Jining City, PR China \\ ${ }^{2}$ Nursing Department, Affiliated Hospital of Jining Medical College, Shandong Province, Jining City PR China \\ *Corresponding author: immunolife@126.com
}

Received August 04, 2014; Revised August 27, 2014; Accepted August 31, 2014

\begin{abstract}
Objective: To analyze the laboratory results of a Sjögren's syndrome combining autoimmune hepatitis (SS-AIH) with double negative of SSA and SSB (SSA'SSB'). Methods: $10 \mathrm{ml}$ venous blood was collected from the patients, and the blood routine, biochemical and immunological indices were respectively detected. Results: The values of WBC, neutrophiles, ESR, ALT, AST, CRP, IgA and IgG were beyond the corresponding reference ranges, respectively. The antinuclear antibody pattern was nuclear homogenous with the titer of 1:1000. The antibodies to $\mathrm{PM}-\mathrm{Scl}$, AnuA and Rib-P were all positive. In the fluorescence immune test for AIH, anti-mitochondrial antibodies (AMA) was positive. The concentration of CCP was $92.5 \mathrm{U} / \mathrm{ml}$ which also was beyond the reference range. Conclusion: There are certain changes in the laboratory results for the SS-AIH patient with SSA'SSB', and if the changes are the common characters for this kind of disease need further observations in future.
\end{abstract}

Keywords: Sjögren's syndrome, autoimmune hepatitis, SSA, SSB

Cite This Article: Jianwei Zhou, Cui Kong, Zhaocai Zhang, Xinke Chen, Shuo Shi, and Liang Han, "Comprehensive Analysis of Laboratory Results of a Sjögren's Syndrome Patient Combining Autoimmune Hepatitis with Double Negatives of the Sjögren's Ayndrome Antigen A and B." American Journal of Medical Sciences and Medicine, vol. 2, no. 4 (2014): 67-70. doi: 10.12691/ajmsm-2-4-1.

\section{Introduction}

Sjögren's syndrome (SS) is a chronic autoimmune disorder of exocrine glands characterized as an autoimmune exocrinopathy. Because of disable salivary and lacrimal glands, the main symptoms of SS are dry mouth and eyes. If the other glands dysfunction, there will be multiple organs damage. With the damage, there must be series of changes in serum, such as the generation of autoantibodies and the increase of the concentrations of immunoglobulins [1]. As we known, Sjögren's syndrome antigen A (SSA) and Sjögren's syndrome antigen B (SSB) are the two indices included in the antinuclear autoantibody (ANA), and double positives of them $\left(\mathrm{SSA}^{+} \mathrm{SSB}^{+}\right)$are the remarkable changes specific to diagnosing SS [2]. Currently, there are little reports on the SS cases with double negative SSA and SSB (SSA'SSB') [3]. Because the number of this case is low, so the reports focus on the SS of SSA SSB combining autoimmune hepatitis (SS-AIH) simultaneously are rather rare. In this paper, we take such a case as an example to comprehensively analyze the partial indexes of blood routine, biochemistry and immunology, and hope to provide a reference for the diagnosis of SS-AIH with SSA $\mathrm{SSB}^{-}$.

\section{Materials and Methods}

The subject is a male patients, aged 70 years. The case is determined according to the 2002 international diagnosis standard of SS. Tumor and infectious diseases, including the infections of hepatitis virus, tubercle bacillus and mycoplasma, are excluded. The study is approved by the local ethic committee, and the informed consent is signed by the patient.

$10 \mathrm{ml}$ venous blood is collected, $2 \mathrm{ml}$ and $8 \mathrm{ml}$ is respectively poured into EDTA- and normal tubers. The former is used to detect hematological indices with 2100 Sysmex Analyzer; the latter is for the biochemical detection with Hitachi 7600 (Hitachi Ltd., Japan) and immunological test. The immunological test includes indirect immunofluorescence assay (IIFA) and immunoblotting test (IBT), which are respectively performed with BEELINE 220s (Hob Ltd., China) and Blotray 866 (Rayto Ltd., China). The concentration of anti-cyclic citrullinated peptide antibodies (CCP-Ab) is measured with Enzyme-linked immunosorbent assay (ELISA). All the reagents are bought from Hob Ltd. of Suzhou, China. 


\section{Results}

In the hematological indices, the values of WBC, neutrophile and ESR are beyond the corresponding reference ranges (Table 1 ). The biochemical indexes such as alanine transaminase (ALT), aspartate aminotransferase (AST), acute reaction protein (CRP), immunoglobulin A (IgA) and immunoglobulin $G$ (IgG) are higher than the maximums of their reference ranges, respectively (Table 2).

Table 1. Results of blood routine of the patient with SS-AIH

\begin{tabular}{lcc}
\hline Items & Results & Average values \\
\hline WBC & $10.79 \times 10^{9} / \mathrm{L}$ & $3.6-9.5 \times 10^{9} / \mathrm{L}$ \\
NEU & $9.69 \times 10^{9} / \mathrm{L}$ & $1.8-6.3 \times 10^{9} / \mathrm{L}$ \\
RBC & $4.93 \times 10^{12} / \mathrm{L}$ & $4.3-5.5 \times 10^{12} / \mathrm{L}$ \\
HCT & $39.7 \%$ & $40-50 \%$ \\
PLT & $172 \times 10^{9} / \mathrm{L}$ & $125-350 \times 10^{9} / \mathrm{L}$ \\
ESR & $72 \mathrm{~mm} / \mathrm{h}$ & $0-15 \mathrm{~mm} / \mathrm{h}$ \\
\hline
\end{tabular}

WBC, white blood cell; NEU, neutrophile; RBC, red blood cell; HCT, hematocrit; PLT, plate.

Table 2. Serum biochemical results of the patients with SS-AIH

\begin{tabular}{ccc}
\hline Items & Results & Reference values \\
\hline $\mathrm{ALT}$ & $108.8 \mathrm{U} / \mathrm{L}$ & $9-50 \mathrm{U} / \mathrm{L}$ \\
$\mathrm{AST}$ & $119.0 \mathrm{U} / \mathrm{L}$ & $15-40 \mathrm{U} / \mathrm{L}$ \\
$\mathrm{TP}$ & $76.8 \mathrm{~g} / \mathrm{L}$ & $65-85 \mathrm{~g} / \mathrm{L}$ \\
$\mathrm{GLO}$ & $40.0 \mathrm{~g} / \mathrm{L}$ & $20-40 \mathrm{~g} / \mathrm{L}$ \\
$\mathrm{RF}$ & $194.1 \mathrm{U} / \mathrm{ml}$ & $0-30 \mathrm{U} / \mathrm{ml}$ \\
$\mathrm{CRP}$ & $12.95 \mathrm{mg} / \mathrm{L}$ & $0-10 \mathrm{mg} / \mathrm{L}$ \\
IgA & $5.2 \mathrm{~g} / \mathrm{L}$ & $0.5-2.2 \mathrm{~g} / \mathrm{L}$ \\
IgM & $1.3 \mathrm{~g} / \mathrm{L}$ & $0.7-3.3 \mathrm{~g} / \mathrm{L}$ \\
IgG & $20.5 \mathrm{~g} / \mathrm{L}$ & $8-16 \mathrm{~g} / \mathrm{L}$ \\
$\mathrm{Cr}$ & $54.3 \mathrm{umol} / \mathrm{L}$ & $25-123 \mathrm{umol} / \mathrm{L}$ \\
$\mathrm{BUN}$ & $4.55 \mathrm{mmol} / \mathrm{L}$ & $2.2-7.2 \mathrm{mmol} / \mathrm{L}$ \\
\hline
\end{tabular}

AST, alanine aminotransferase; AST, aspartate aminotransferase; TP, total protein; GLO, globulin; RF,

rheumatoid factor; CRP, C-reaction protein; IgA, immunoglobulin A; IgM, immunoglobulin M; IgG, immunoglobulin G; Cr, ceartinine; Bun: blood urea nitrogen
In the IIFA results of ANA, the pattern is nuclear homogenous, and the titer is high to 1:1000 (Figure 1). In those of Antibody spectrum for Autoimmune Hepatitis (AIHAs), the antibody to mitochondrial (AMA) exhibits positive (Figure 2). In the immunoblotting test, the antibodies to polymyositis/scleroderma (PM-Scl), nucleosome (AnuA), ribosomal-P (Rib-P) and mitochondrial-2 (AMA-2) are all positive. In the four indices of AIHAs, the antibody to AMA-2 is also positive (Table 3). The concentration of $\mathrm{CCP}-\mathrm{Ab}$ is $92.5 \mathrm{U} / \mathrm{ml}$ which is beyond its reference value.

Table 3. Immunological results of the patients with SS-AIH of SSA SSB

\begin{tabular}{ccccc}
\hline Immunoblotting test & Items & Results & Items & Results \\
\hline & nRNP & - & CENPB & - \\
& Sm & - & PCNA & - \\
& SSA/52kd & - & dsDNA & - \\
Antinuclear antibody & SSA/60kd & - & AnuA & + \\
spectrum & SSB & - & AHA & - \\
& Scl-70 & - & Rib-P & + \\
& PM-Scl & + & AMA-M2 & + \\
& Anti-Jo-1 & - & & + \\
$\begin{array}{c}\text { Antibody spectrum for } \\
\text { Autoimmune Hepatitis }\end{array}$ & ASMA & - & AMA-M2 & + \\
\hline
\end{tabular}

-, negative; +, positive; nRNP, antibody to ribonuclear protein; Sm, antibody to sm; SSA/52kd, antibody to Sjögren's syndrome antigen A (52kd); SSA/60kd, antibody to Sjögren's syndrome antigen A (60kd); SSB, antibody to Sjögren's syndrome antigen B; Scl-70, antibody to topoisomerase; PM-Scl, antibody to polymyositis/scleroderma; Jo-1, antibody to histidyl-tRNA synthetase; CENPB, antibody to centormere B; PCNA, antibody to proliferation cell nuclear antigen; dsDNA, antibody to double-strain DNA; AnuA, antibody to nucleosome; AHA, antibody to histone; Rib-P, antibody to ribosomal-P; AMA-M2, antibody to mitochondrial M2; ASMA, antibody to smooth muscle; LKM-1, antibody to liver/kidney microsomal 1; LC-1, antibody to liver cells.

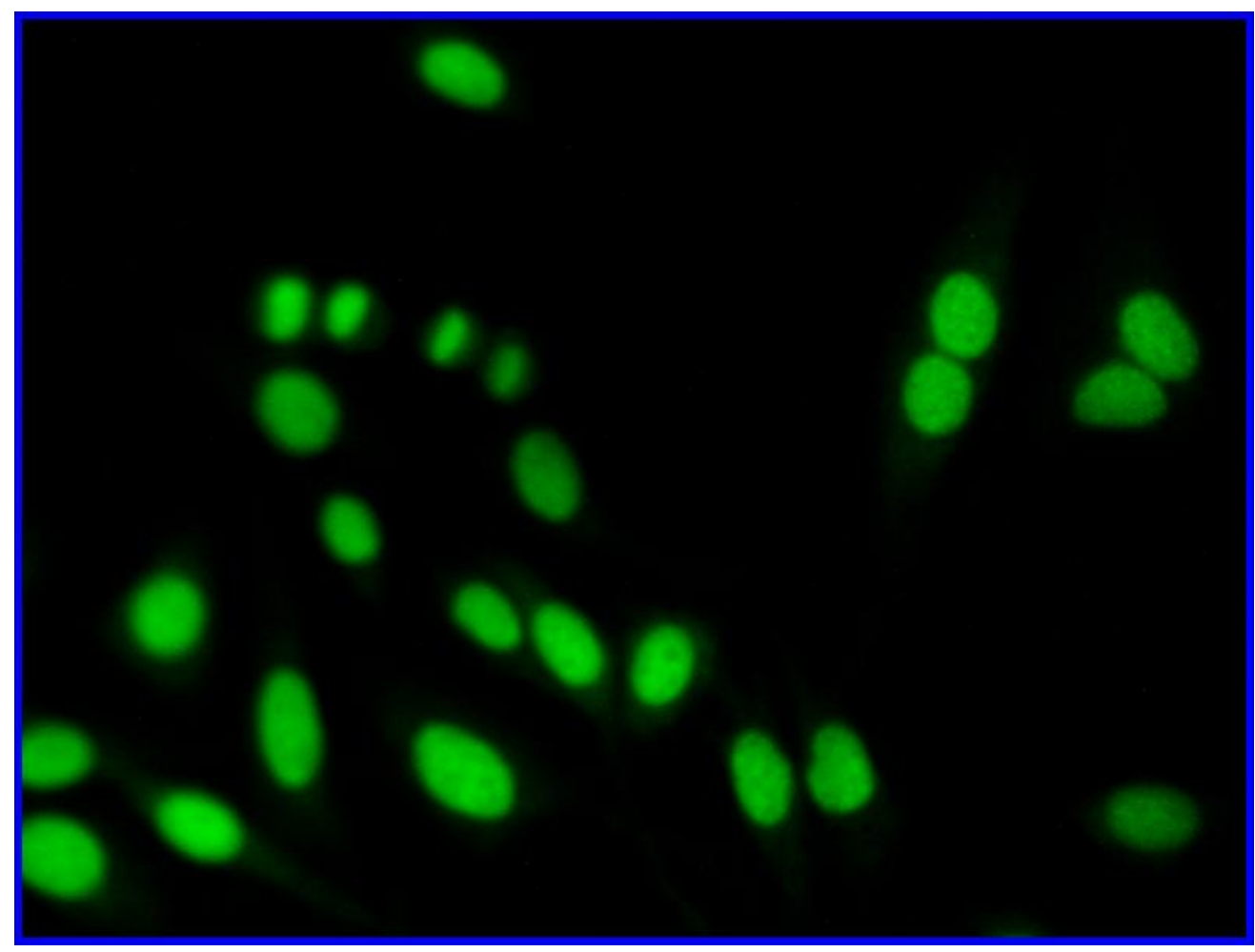

Figure 1. The result of ANA with immunofluorescence assay $(40 \times)$ 


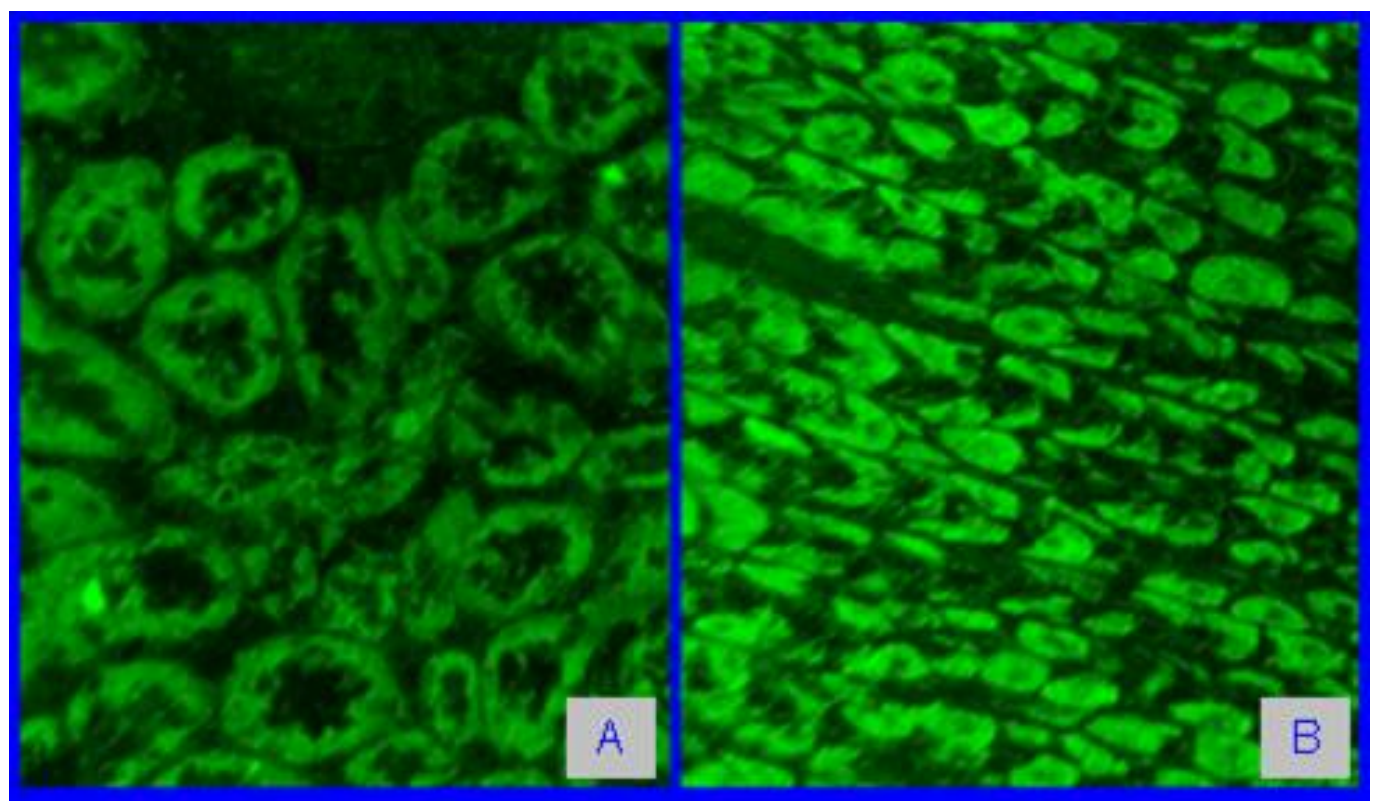

Figure 2. The result of AIH detecting spectrum with immunofluorescence assay $(20 \times)$ : A, stomach cells the rat; B, kidney cells of the rat

\section{Discussion}

There were usually some complications, such as the pathological changes in lung, kidney, and nervous system. According to the report [4], the occurrence rates for them were $17.2 \%, 16.8 \%$ and $14.5 \%$, respectively. However, there were few reports on SS complicated with AIH. In this paper, the patient with SS-AIH of SSA ${ }^{-} S^{-}$was observed. As the results shown, ANA pattern was nuclear homogenous with the titer of 1:1000, which probably bespeak that there was strong autoimmune response in the patient. In the results for autoantibodies, PM-Scl, AnuA and Rib-P were positive. This possible indicated that the combination of nuclear homogenous pattern plus the three antibodies is one of the common characters of SS-AIH with SSA'SSB- PM-Scl mainly locates at nucleus and relates to Overlap Syndrome [5], and it may be an important factor which indicates the occurrence of AIH in SS patients with SSA'SSB. AnuA and Rib-P are the indexes relate to systemic lupus erythematosus (SLE) [6,7], especially, the level of AnuA increased in SLE complicated with liver injury [8]. In this study, the indices related to liver also were higher than the corresponding reference range, and these data probably validate that AnuA also is an indicator for liver injury in the AIH-SS patients of SSA'SSB'.

WBC, neutrophiles and ESR are the inflammatory indices for some infectious disease. In the present case, the levels of them were all beyond the corresponding reference ranges, which probably indicated that there were inflammatory responses caused by liver injury. ESR usually increased in some SS patients, and ESR plus CCP were taken as the diagnosis indexes for rheumatoid arthritis (RA), but what was the exact meaning for the simultaneous increase of the two indices in this patient remained unclear. In biochemical results, the levels of ALT, AST, CRP, IgA and IgG were beyond the corresponding reference ranges, this was consistent with the Yao's report [9]. Differently, although IgG and IgA increased, the level of GLO was normal, and there was no hypergammaglobulinemia observed [10]. In our opinions, they maybe were the just features of AIH-SS with SSA $\mathrm{SSB}^{-}$.

\section{Conclusion}

There are certain changes for hematological, biochemical and immunological indices in such a case with SS-AIH of SSA'SSB', and if the positive changes of these indices can be taken as the specific characteristic for diagnosing the disease need further study.

\section{Financial Disclosure}

This article was supported by the Provincial Science and Technology Development Project (Grant 2012YD18054), Provincial Nature Science Foundation (Grant ZR2012HL29), the High School Science and Technology Plan Project (Grant J11LF18), the Population and Family Planning Commission (Grant [2011]13), the Development Plan Project of Jining Science and Technology Bureau of Shandong Province (Grant [2011]57), the Youth Foundation of Jining Medical College (Grant [2011]01), and the Miaopu Program of Affiliated Hospital of Jining Medical College (Grant JYFY-MP-2013-09).

\section{Conflicts of Interest}

All the authors declare that there is no conflict of interest.

\section{References}

[1] Li Z, Chen S, “Clinic rheumatism handbook", Bejing, People publishing house, 2008.

[2] Liu Y, Wang YF, Wang KL, Lv FF, "Prevalence and significance of immunoglobulin G-anti-cyclic citrullinated peptide antibodies in primary Sjogren's syndrome patients”, Beijing Da Хие Хие Вао, 46(3): 478-482, 2014, 
[3] Mekinian A, Nicaise-Roland P, Chollet-Martin S, Fain O, Crestani B, “Anti-SSA Ro52/Ro60 antibody testing by immunodot could help the diagnosis of Sjogren's syndrome in the absence of antiSSA/SSB antibodies by ELISA", Rheumatology (Oxford), 52(12): 2223-2228, 2013.

[4] $\mathrm{Xu} \mathrm{YJ}, \mathrm{Wu} \mathrm{HX}$, "The correlation between immunological abnormality and systemic involvement in primary Sjögren’s syndrome”, Immunological Journal, 29(3): 243-246, 2013.

[5] Varga J, "Systemic sclerosis: an update", Bull NYU Hosp Jt Dis, 66: 198-202, 2008

[6] Sheng ML, Hao JH, Tao JH, Zhang H, Zhang ZH, Zhang GQ, et al., "Association of expression of serum antinucleosome antibody family and SLE disease activity index", Chin J Health Lab Tech, 32(1): 95-100, 2013
[7] Hu ZG, Chen GQ, Zou YH, Yuan JS, Zhou Y, “Anti-ribosomal P0 protein antibodies in Systemic Lupus Erythmatosus and their clinical diagnosi significance”, Chin J Nosocomiol, 20(22): 36303632, 2010.

[8] Yu YX, Zhu CX, Chi SH, Wang HY, "The correlation of plasma AnuA level with activity and organ damage in systemic lupus erythematosus patients", China Journal of Modern Medicine, 23(9): 50-54, 2013.

[9] Yao Z, Long L, Li ZG, "Comparisons of clinical characteristics of primary Sjögren's syndrome onset at different ages”, Chin Rheumatol, 10(11): 683-686, 2006.

[10] Wu CL, Liu HN, Yang PT, Zhao LH, Xiao WG, "Relationship of CCR7 expression on peripheral blood T lymphocyte with the disease activity of Sjögren’s syndrome”, Immunological Journal, 26(11): 953-955, 961, 2010. 